EXTENDED REPORT

\title{
Enhanced gene transfer to arthritic joints using adeno-associated virus type 5: implications for intra- articular gene therapy
}

\author{
J Adriaansen, S W Tas, P L Klarenbeek, A C Bakker, F Apparailly, G S Firestein, \\ C Jorgensen, M J B M Vervoordeldonk, P P Tak
}

See end of article for authors' affiliations

Correspondence to: Professor P P Tak, Academic Medical Centre, Division of Clinical Immunology and Rheumatology, Meibergdreef 9, Room F4$218,1105 \mathrm{AZ}$ Amsterdam, The Netherlands; P.P.Tak@ amc.uva.nl

Accepted 3 May 2005 Published Online First 5 May 2005
Background: Gene therapy of the joint has great potential as a new therapeutic approach for the treatment of rheumatoid arthritis (RA). The vector chosen is of crucial importance for clinical success. Objective: To investigate the tropism and transduction efficiency in arthritic joints in vivo, and in synovial cells in vitro, using five different serotypes of recombinant adeno-associated virus (rAAV) encoding $\beta$ galactosidase or green fluorescent protein genes.

Methods: rAAV was injected into the ankle joints of rats with adjuvant arthritis after the onset of disease. Synovial tissue was examined at different time points for $\beta$-galactosidase protein and gene expression by in situ staining and polymerase chain reaction (PCR) analysis, respectively. In addition, the ability of rAAV to transduce primary human fibroblast-like synoviocytes from patients with RA was investigated in vitro. Results: Intra-articular injection of the rAAV5 serotype resulted in the highest synovial transduction, followed by much lower expression using rAAV2. Expression of the transgene was already detectable 7 days after injection and lasted for at least 4 weeks. Only background staining was seen for serotypes 1 , 3, and 4. Importantly, there was a minimal humoral immune response to rAAV5 compared with rAAV2. Additionally, it was found that both rAAV2 and rAAV5 can efficiently transduce human fibroblast-like synoviocytes obtained from patients with RA.

Conclusion: Intra-articular rAAV mediated gene therapy in RA might be improved by using rAAV5 rather than other serotypes.
$\mathrm{R}$ heumatoid arthritis (RA) is a chronic inflammatory disease characterised by persistent joint swelling and progressive destruction of cartilage and bone. Biological agents targeting cytokines, like tumour necrosis factor $\alpha$ or interleukin 1 , and their receptors have proved useful as specific treatments for RA. ${ }^{1-4}$ However, the need for continuous treatment with multiple injections of a recombinant protein, the relatively high systemic doses necessary to achieve constant therapeutic levels in the joints, and the reported side effects hamper this therapeutic approach.

An alternative approach might be to use intra-articular gene therapy to deliver therapeutic genes directly to the synovium in order to have the protein synthesised at the site of inflammation. Synoviocytes can be readily accessed by intra-articular injection, making them good targets for gene delivery. They are resident cells in the human synovium and have a low mitotic rate. ${ }^{5}$ Therefore, they are likely to express transduced genes for a considerable length of time.

Viral mediated gene transfer is currently the most efficient system for delivering therapeutic proteins in vivo. Adenoassociated virus (AAV) especially holds great promise as a new vector and appears to be safe. ${ }^{67} \mathrm{AAV}$ is a single stranded DNA virus that does not induce a significant immune response and is not associated with disease in humans. The ability of AAV to mediate expression of therapeutic genes has been well established in several animal models of arthritis. ${ }^{8-12}$ Recombinant AAV2 (rAAV2) has been validated for gene therapy in human clinical trials in cystic fibrosis, $\alpha_{1}$ antitrypsin deficiency, and haemophilia. ${ }^{13-15}$ rAAV vectors are particularly useful in targeting slowly dividing cells and in the treatment of chronic disease because of their potential for site-specific integration into the host genome or formation of stable episomal DNA, both of which result in long term gene expression. ${ }^{16}{ }^{17}$

All studies reported so far have been performed using rAAV serotype 2. However, rAAV2 vectors are rather inefficient in transducing some cell types. ${ }^{18-20}$ In addition, the prevalence of antibodies against this serotype is high in the human population. ${ }^{6}$ Many people carry antibodies that can neutralise infection of cells with rAAV2 in vitro, and it is widely assumed that this is also relevant in vivo. ${ }^{21} 22$ At this moment at least eight naturally occurring serotypes of AAV have been isolated, cloned, and sequenced (AAVI to AAV8). Although these serotypes are very similar in genetic structure and biological properties, the capsid genes show as little as 50$60 \%$ homology in DNA sequence, resulting in viral shells that have a different amino acid composition. ${ }^{63}$ The use of nontype $2 \mathrm{AAV}$ capsids to deliver transgenes to target cells might offer two important advantages over conventional AAV2 vectors: $(a)$ an overall broader host range, and $(b)$ an escape from anti-AAV2 immune responses, allowing vector (re-) administration despite existing immunity against AAV2.

In an effort to compare the role of serotype-specific virion shells on synovial transduction, we cloned the serotype capsid encoding domains into a common vector backbone containing AAV2 replication genes. This strategy allows the packaging of AAV2 inverted terminal repeat vectors into

Abbreviations: AIA, adjuvant induced arthritis; $\mathrm{CMV}$, cytomegalovirus; FLS, fibroblast-like synoviocyłes; GC, genomic copies; gDNA, genomic DNA; GAPDH, glyceraldehyde-3-phosphate dehydrogenase; GFP, green fluorescent protein; IOD, integrated optical density; MOD, mean optical density; PBS, phosphate buffered saline; PCR, poymerase chain reaction; RA, rheumatoid arthritis; $r A A V$, recombinant adenoassociated virus 
specific virions of each serotype, resulting in hybrid serotype vectors differing only in their capsids. In the study presented here we compared the transduction efficiency of five different recombinant AAV serotypes (rAAVI to rAAV5) encoding the $E$ coli derived reporter gene, $\beta$-galactosidase $(\beta-G a l)$, to transduce arthritic synovium in vivo. In addition, we examined the transduction efficacy of rAAV containing the enhanced green fluorescent protein (GFP) gene in primary human RA fibroblast-like synoviocytes (FLS).

\section{METHODS}

\section{Production of rAAV}

All rAAV constructs were derived from AAV2 and driven by the cytomegalovirus (CMV) immediate early promoter. rAAV was produced by co-transfection of 293 HEK cells with $150 \mu \mathrm{g}$ packaging plasmid (pDG for AAV2 ${ }^{24}$ and pDP1, pDP3, pDP4, and pDP5 for AAVl, AAV3, AAV4, and AAV5, ${ }^{25}$ respectively) and $50 \mu \mathrm{g}$ vector plasmid containing the LacZ or the GFP gene with the CMV promoter and the bovine growth hormone polyA region between the AAV2 inverted terminal repeat vectors, by the calcium phosphate method. Plasmids were purified with Qiafilter plasmid Giga Kits (Qiagen, Alameda, USA).

Seventy two hours after transfection, the cells were lysed using benzonase (Merck, Whitehouse Station, USA) to a final concentration of $75 \mathrm{U} / \mathrm{ml}$. Crude cell lysates were further purified with iodixanol gradients as described earlier. ${ }^{26}$ The gradient layer containing the virus was extracted, diluted 10 times with phosphate buffered saline (PBS) and concentrated to about $2 \mathrm{ml}$ with centricon devices (YM-100, Millipore Corporation, Billerica, USA). Stock viral titres ranging between $10^{11}$ and $10^{12}$ genomic copies $(\mathrm{GC}) / \mathrm{ml}$ in saline were reached.

\section{Detection of viral genomic copies (GC) by quantitative polymerase chain reaction (Q-PCR)}

To determine the viral titre as GC (full viral particles), rAAV samples were first diluted 10 -fold in PBS. Samples were incubated with $10 \mu \mathrm{l}$ of MagneSil BLUE suspension (Promega), and the viral DNA was isolated using the MagnaBot 96 Magnetic Separation Device (Promega) according to the supplier's instructions.

Dilutions of the purified viral DNA or the genomic DNA (gDNA) isolated from the joints and organs were added to the PCR mix containing $0.5 \mu \mathrm{mol} / \mathrm{l}$ of the CMV forward primer (5'-AATGGGCGGTAGGCGTGTA-3') (Invitrogen), $0.5 \mu \mathrm{mol} / \mathrm{l}$ of the CMV reverse primer $\left(5^{\prime}\right.$-AGGCGATCTGA CGGTTCACTAA-3') (Invitrogen), and SYBR green PCR master mix buffer (Applied Biosystems, Foster City, USA). PCR reactions were performed using the Abi prism SDS7000 sequence detection system (Applied Biosystems, Foster City, USA).
A

rAAV1

rAAV2
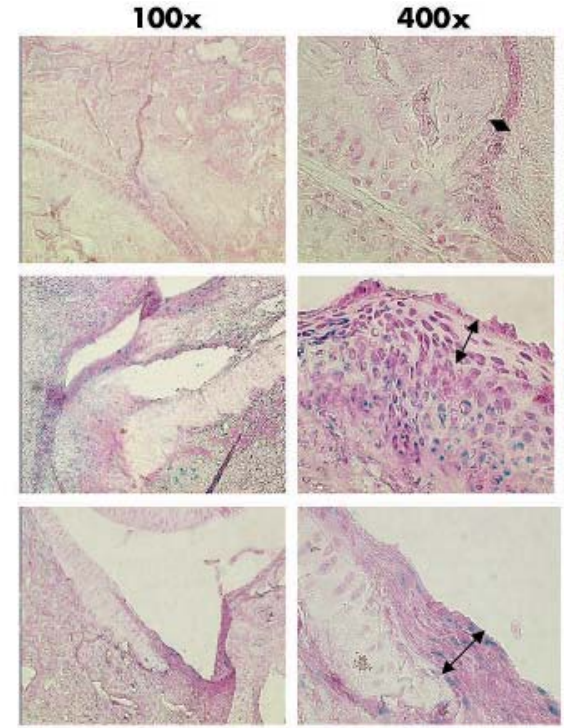

rAAV3

rAAV4
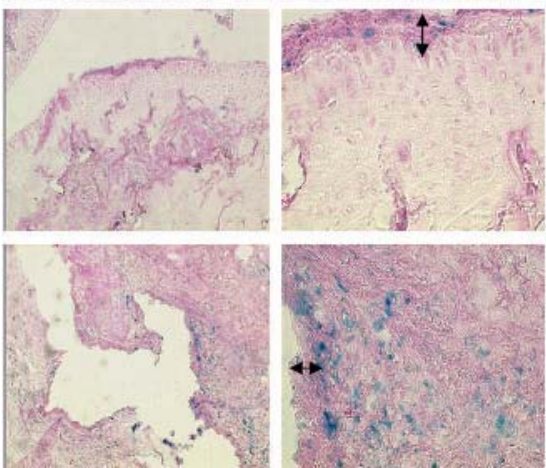

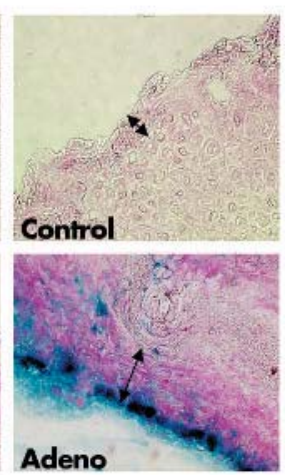

Adeno

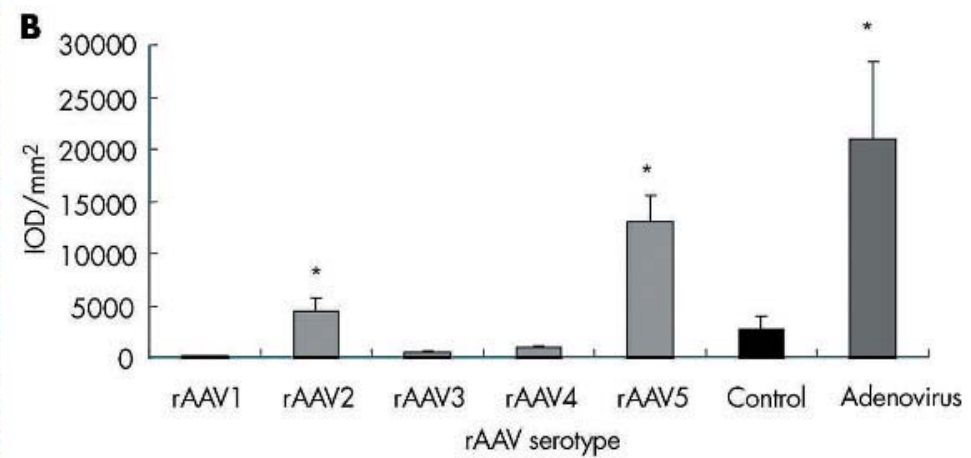

Figure $1 \quad \beta$-Gal expression in rat synovial tissue 2 weeks after intra-articular injection of different rAAV serotypes. Joints were snap frozen and sections were cut and stained in situ for $\beta$-Gal activity and counterstained with nuclear red. Representative cryosections of right ankle joints of rats with adjuvant induced arthritis (AIA), injected with $6.1 \times 10^{10} \mathrm{GC} \mathrm{rAAV}$, Ad.LacZ as a positive control or saline as a negative control are shown (magnification $\times 100, \times 400$ ). The lining layer is indicated by arrows (A). Tissue sections were quantified for $\beta$-Gal expression by computer assisted digital image analysis (B). Values are expressed as mean (SD) cumulative $\mathrm{IOD} / \mathrm{mm}^{2}$. ${ }^{*} \mathrm{p}<0.05$ as compared with the control group, Mann-Whitney $U$ test. 


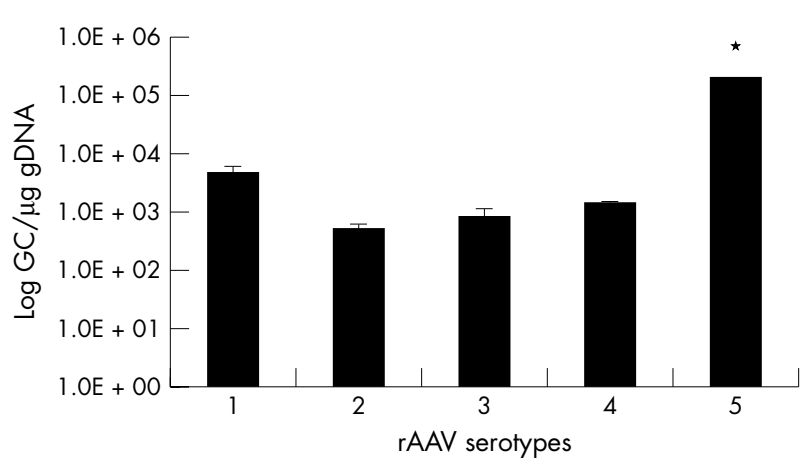

Figure 2 Viral genomic copies in the right ankle joints of rats injected with different rAAV serotypes. Two weeks after intra-articular rAAV injection, gDNA was isolated from crushed ankle joints and analysed for viral GC by quantitative PCR. Specific primers against the CMV promoter of the transgene were used. No viral DNA was found in control or left joints. Values are expressed as mean (SD) $\log G C / \mu g$ DNA. ${ }^{*} \mathrm{p}<0.05$.

\section{Animals}

Pathogen-free male Lewis rats (150-200 g) were obtained from Harlan Sprague Dawley Inc (Horst, The Netherlands) and were maintained in our central animal facility. The ethical animal care and use committee of the University of Amsterdam approved all experiments.

\section{Local gene transfer}

All rats were immunised at the base of the tail with $1 \mathrm{mg}$ of Mycobacterium tuberculosis H37RA (Difco, Detroit, USA) in $0.1 \mathrm{ml}$ mineral oil on day $0 .{ }^{27}$ Paw swelling was usually seen by days 10-12 and measured daily by water displacement plethysmometry. At day 12, the skin was disinfected with ethanol and $6.1 \times 10^{10} \mathrm{GC}$ rAAVl-5 containing the gene encoding LacZ (further referred to as rAAV1-5) was injected anterolaterally into the right ankle joint in a total volume of $50 \mu \mathrm{l}$ saline using a 31 -gauge needle on a glass syringe. ${ }^{28}$ Adenovirus containing the LacZ gene (adjusted to $6.1 \times 10^{10}$ GC/animal) served as a positive control and diluent was used as negative control. Rats injected with rAAV and control rats were killed 2 weeks after intra-articular injection by $\mathrm{CO}_{2}$ inhalation, whereas adenovirus-injected rats were killed 2 days after injection $(n=6 /$ group). Serum samples were taken from the vena cava. Hind paws, spleen, heart, lung, liver, and kidney were collected.

To investigate the transgene expression at different time points, a second experiment was performed using a different

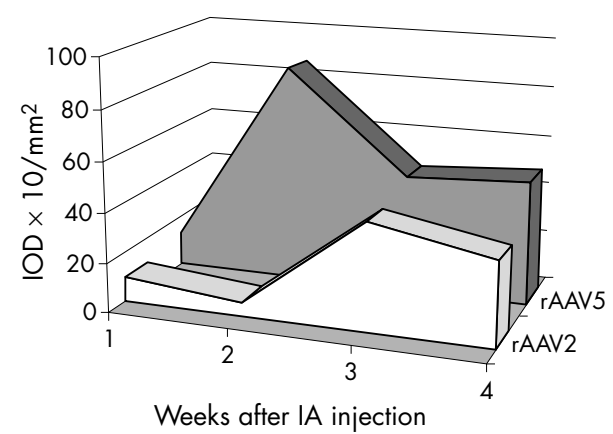

Figure $3 \beta$-Gal expression in rat synovial tissue 1, 2, 3, and 4 weeks after intra-articular (IA) injection of $1.14 \times 10^{10} \mathrm{GC}$ rAAV serotype 2 or 5 , quantified by digital image analysis. Injected joints were snap frozen and cryosections were stained in situ for $\beta$-Gal activity. Staining was evaluated by computer assisted analysis and expressed as IOD $\times 10 /$ $\mathrm{mm}^{2}$. batch of rAAV. Animals received an intra-articular injection of $1.14 \times 10^{10}$ GC rAAV2 or rAAV5 and were killed as described 1, 2, 3, and 4 weeks after injection ( $\mathrm{n}=3$ /group). Serum samples were obtained from all groups by tail bleeding before rAAV injection and by vena cava punction as the animal was killed.

\section{Detection of $\beta$-galactosidase activity}

Joints were fixed in $4 \%$ formalin, decalcified using EDTA, and snap frozen in liquid nitrogen. Sections $(10 \mu \mathrm{m})$ were cut on a cryostat and mounted on glass slides (Star Frost adhesive slides; Knittelgläser, Germany). Subsequently, detection of $\beta$ Gal activity was performed by X-Gal staining as described previously. ${ }^{28}$ After washing with PBS, sections were counterstained with nuclear red. The sections were evaluated by digital image analysis.

\section{Digital image analysis}

Six randomly selected fields within each section were chosen for digitising the positive signal. These images were acquired on an Olympus microscope (Olympus, Tokyo, Japan), captured using a Charged Coupled Device video camera (Sony, Tokyo, Japan), and digitised with a PV100 multimedia 16 bit colour video digitiser card. In the resultant colour images the area of positive staining and the mean optical density (MOD) were measured by a macro program as described earlier. ${ }^{29}{ }^{30}$ The MOD is proportional to the cellular concentration of protein. The integrated optical density (IOD) is equal to the MOD multiplied by the area of positive staining.

\section{PCR detection of LacZ}

Ankle joints (trimmed of skin) and organs were snap frozen in liquid nitrogen, pulverised using a mortar, and homogenised in TRIzol Reagent ( $100 \mathrm{mg} / \mathrm{ml}$; GibcoBRL Life Technologies, Gaithersburg, USA) using a tissue homogeniser. Total RNA was isolated from the aqueous phase and gDNA was extracted from the phenol-chloroform phase according to the manufacturer's instructions. gDNA was stored for quantitative PCR analysis. RNA was dissolved in DEPC-water and cDNA was synthesised from $1 \mu \mathrm{g}$ RNA using Superscript II RT (Invitrogen) according to the manufacturer's instructions.

For PCR, $10 \mu \mathrm{l}$ of cDNA solution was amplified using $25 \mu \mathrm{l}$ of AccuPrime SuperMix I (Invitrogen), $215 \mathrm{mmol}$ of the LacZ forward primer (5'-GCATCGAGCTGGGTAATAAGCGTTGG CAAT-3'), and $215 \mathrm{mmol}$ of the LacZ reverse primer (5'GACACCAGACCAACTGGTAATGGTAGCGAC-3') in a total volume of $50 \mu \mathrm{l}$. Rat glyceraldehyde-3-phosphate dehydrogenase (GAPDH) was used as an internal control (forward: 5'-CGGTGTCAACGGATTTGGC-3', reverse: 5'-CCATGCCAGT GAGCTTCCC-3'). Amplification was then performed in a thermocycler (MJ Research, Inc, Waltham, USA) as follows: 3 minutes at $95^{\circ} \mathrm{C}$, followed by 35 cycles at $94^{\circ} \mathrm{C}$ for 1 minute, $58^{\circ} \mathrm{C}$ for 90 seconds, and $72^{\circ} \mathrm{C}$ for 1 minute, respectively,

Table 1 Detection of viral genomic copies in injected joints after intra-articular injection of rAAV2 or rAAV5

\begin{tabular}{lll}
\hline & rAAV2 & rAAV5 \\
\hline Week 1 & $6.45 \times 10^{4}\left(2.12 \times 10^{3}\right)$ & $1.42 \times 10^{7}\left(3.39 \times 10^{3}\right)$ \\
Week 2 & $1.83 \times 10^{3}\left(5.87 \times 10^{2}\right)$ & $1.37 \times 10^{6}\left(5.17 \times 10^{3}\right)$ \\
Week 3 & $<10$ copies & $4.37 \times 10^{6}\left(2.25 \times 10^{3}\right)$ \\
Week 4 & $<10$ copies & $2.24 \times 10^{5}\left(1.49 \times 10^{3}\right)$ \\
\hline
\end{tabular}

Genomic DNA was isolated from crushed ankle joints 1, 2, 3, or 4 weeks after injection. Quantitative PCR was performed with specific primers for the CMV promoter of the transgene. Values are expressed as mean (SD) $\mathrm{GC} / \mu \mathrm{g} \mathrm{gDNA}$. 
followed by a final extension phase at $72{ }^{\circ} \mathrm{C}$ for 10 minutes. The PCR products were analysed by standard agarose gel electrophoresis on a $0.9 \%$ agarose gel containing ethidium bromide for ultraviolet assisted visualisation of the $622 \mathrm{bp}$ product. For semiquantitative analysis, the gel was digitised and the signal was corrected for background and area. Thereafter, the LacZ/GAPDH ratio was determined using Quantity One software (Biorad, Hercules, USA).

\section{Formation of anti-rAAV neutralising antibodies in serum}

Neutralising antibody titres were analysed by assessing the ability of serum antibodies to inhibit the transduction of rAAV into COS cells. Various dilutions of serum (1:200 to $1: 51200)$ were preincubated with rAAV at $37^{\circ} \mathrm{C}$ for 1 hour and then added to $80 \%$ confluent COS cells. Thereafter, cell cultures were incubated with rAAV in the presence of serum for 20 hours, and LacZ expression was measured by $\beta$-Gal staining as described earlier. The antibody titre was represented by the highest dilution that did not inhibit $\beta$-Gal expression compared with cells incubated with rAAV alone.

\section{In vitro transduction of human FLS}

Small-bore arthroscopy $(2.7 \mathrm{~mm}$ arthroscope, Storz, Tuttlingen, Germany) was performed under local anaesthesia in three patients with established RA. ${ }^{31}{ }^{32}$

The biopsy specimens were enzymatically dispersed and cultured as described previously ${ }^{33}$ and the FLS obtained were plated on six-well dishes (Flacon, Bedford, USA) at $1 \times 10^{5}$ / well. After incubation for 15 hours, $1 \times 10^{8}$ GC of rAAVl-5 containing the gene for GFP was added to each well in medium containing $10 \%$ fetal calf serum. The cells were cultured for 72 hours and marker gene expression was evaluated by fluorescent microscopy and flow cytometric analysis. Three independent primary FLS cell lines from three patients were used for these experiments.

\section{Flow cytometry}

Transduced FLS were trypsinised, resuspended in Dulbecco's modified Eagle's medium containing $10 \%$ fetal calf serum, and washed in PBS containing $0.01 \%$ (wt/vol) $\mathrm{NaN}_{3}$ and $0.5 \%$ (wt/vol) bovine serum albumin. Analysis of GFP gene expression was performed using a FACS Calibur flow cytometer and CellQuest software (BD Biosciences, Franklin Lakes, USA).

\section{Statistics}

Where applicable, differences in means between groups were determined by Kruskal-Wallis test, followed by a MannWhitney U rank sum test. $\mathrm{p}<0.05$ was considered significant.
All analyses were done using SPSS version 11.5 (SPSS, Chicago, USA).

\section{RESULTS}

\section{Comparative efficiency of five rAAV serotypes}

To compare the transduction efficiency of rAAV serotypes in the joints, rAAVl-5 were injected into the right ankle joints of rats ( $n=6 /$ group) on day 12 after adjuvant immunisation. Joints were harvested 2 weeks after injection and stained in situ to measure $\beta$-Gal expression. Staining was quantified by digital image analysis. The strongest expression of $\beta-G a l$ in synovial tissue was detected in arthritic joints injected with rAAV5, followed by a much lower expression using rAAV2 (fig 1B). Strikingly, rAAV transduction resulted in a greater penetration into the synovial tissue than with adenovirus, where $\beta$-Gal expression was limited to the intimal lining layer. No staining could be seen in the control joints (fig lA). No expression above background staining was seen for serotypes 1, 3, and 4. These findings were confirmed by quantitative PCR. In gDNA isolated from crushed joints, the highest number of viral GC was detected using rAAV5 $\left(1.9 \times 10^{5} \mathrm{GC} / \mu \mathrm{g}\right.$ gDNA) (fig 2). Semiquantitative PCR showed the presence of LacZ mRNA in all injected joints, but not in spleen, liver, heart, lung, kidney, or uninjected joints (data not shown).

\section{Duration of transgene expression}

To monitor the transgene expression over time, rAAV2 or rAAV5 were injected into arthritic joints of rats and killed 1 , 2 , 3, or 4 weeks after injection of the vector. For both serotypes transgene expression was detectable 1 week after injection with marked expression for up to 4 weeks, but displayed different expression kinetics. rAAV5 resulted in earlier $\beta$-Gal expression than rAAV2, with higher levels at all time points (fig 3). This was confirmed by quantitative PCR analysis. The number of GC detected in the joints after rAAV5 injection was higher at all time points than with rAAV2 (table 1).

To test if this increased amount of viral GC also results in an increased transcription of the transgene, PCR analysis was carried out using specific primers for LacZ. Figure 4 demonstrates that in rAAV2 as well as in rAAV5 injected animals, high levels of LacZ mRNA were found after 1 week. This rapidly declined in the rAAV2 injected animals, whereas in the rAAV5 injected animals the level of LacZ mRNA remained about $50 \%$ of the levels found after 1 week.

A limited ( $\mathrm{n}=3$ /group) biodistribution study was performed, and no viral DNA or LacZ mRNA was found in the uninjected left joints at any time point. A relatively low amount of GC was found only in the kidney and liver after 1 week, but not at later time points, suggesting minimal,

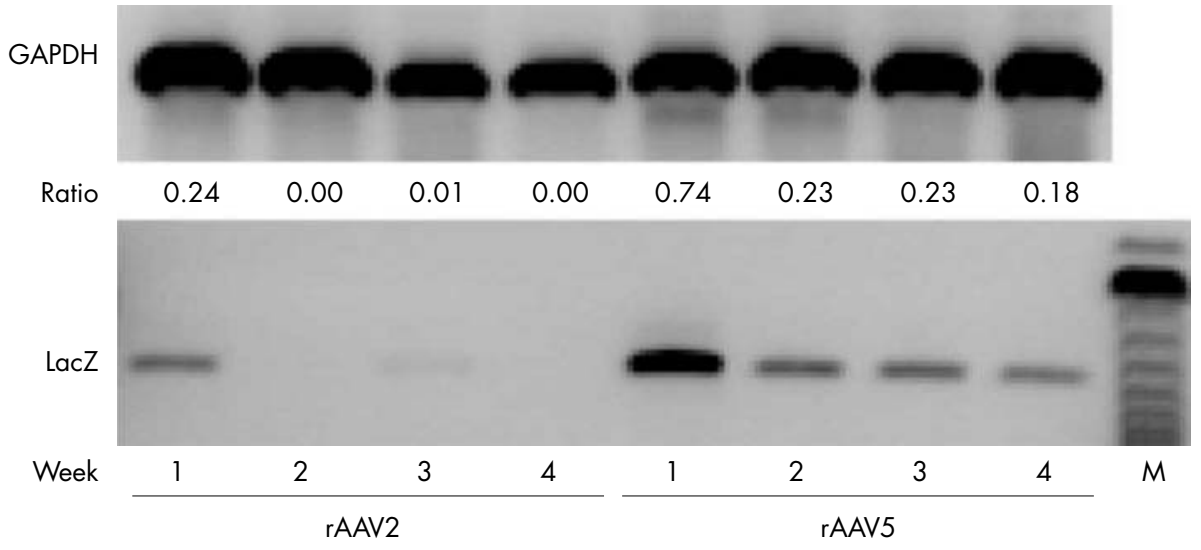

Figure 4 LacZ mRNA in rat ankle joints after intra-articular injection of rAAV2 and rAAV5. Total mRNA was extracted from crushed ankle joints and cDNA was synthesised. PCR was performed using specific primers for the LacZ gene. GAPDH was used as internal control. To correct for differences in GAPDH mRNA, LacZ/ GAPDH ratios are displayed as measured by computer assisted gel quantification. The uninjected left joints as well as the control joints did not show LacZ expression. 

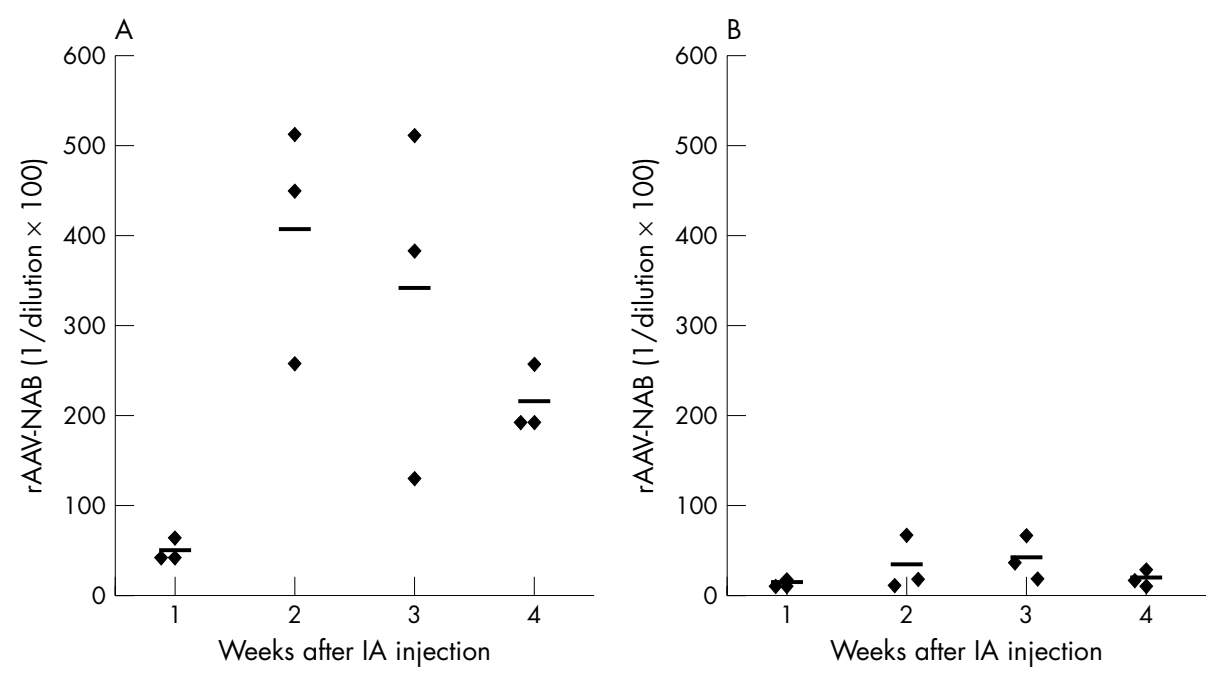

Figure 5 Neutralising antibody (NAB) titres in serum after intra-articular (IA) injection of rAAV2 or rAAV5. Arthritic rats were injected with $1.14 \times 10^{10} \mathrm{GC}$ rAAV2 (A) or rAAV5 (B) into the right ankle joints. Serum samples were obtained 1, 2, 3, and 4 weeks after injection. Titres were calculated as the highest dilution which shows no decrease in number of $\beta$-Gal positive cells compared with wells incubated with rAAV.LacZ alone.

temporary dissemination of the vector (data not shown). In the spleen, liver, heart, lung, kidney, and lymph nodes, no LacZ mRNA was detected at any time point (data not shown).

\section{Formation of rAAV antibodies}

To detect a possible humoral immune response against the rAAV capsid proteins after intra-articular injection, we performed a neutralising antibody assay. The presence of neutralising antibodies before and after rAAV injection was determined in the serum of rats injected with rAAV2 and rAAV5.

Before injection, no antibodies were found in any of the samples. One week after injection, neutralising antibodies were detected, peaking at 2 weeks and slowly decreasing after 3 weeks. Although this tendency was seen for both serotypes, rAAV2 injection obviously induced higher neutralising antibody titres in serum than rAAV5, which induced
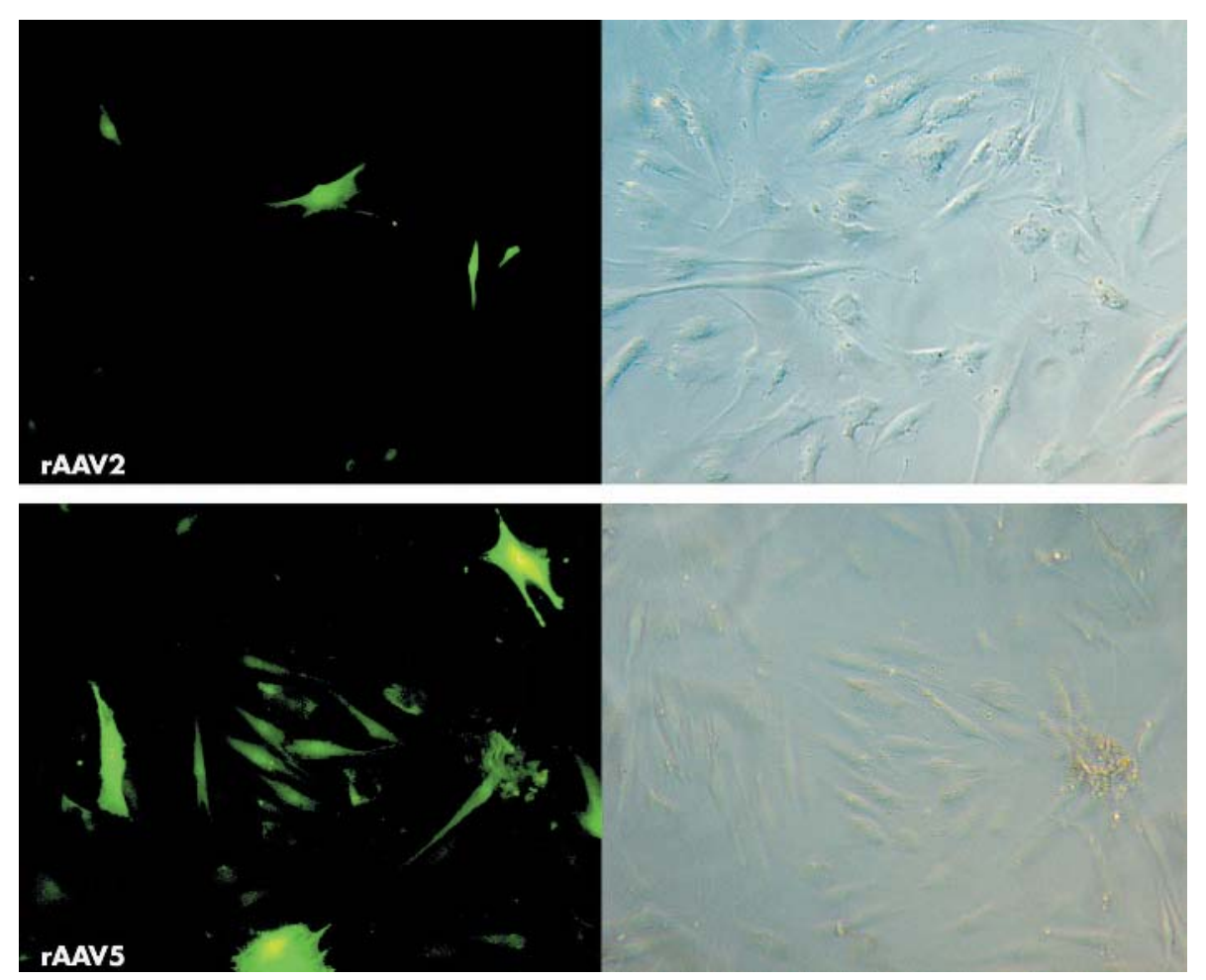

Figure 6 Transduction of FLS with rAAV in vitro. Human FLS isolated from synovial biopsy specimens from patients with RA were incubated with rAAV2.GFP or rAAV5.GFP. After 48 hours of incubation, the cells were fixed and transgene expression was determined by fluorescent microscopy. Representative pictures of three independent experiments using cells from three different patients are shown. Left: fluorescent microscopy, right: phase contrast microscopy. 

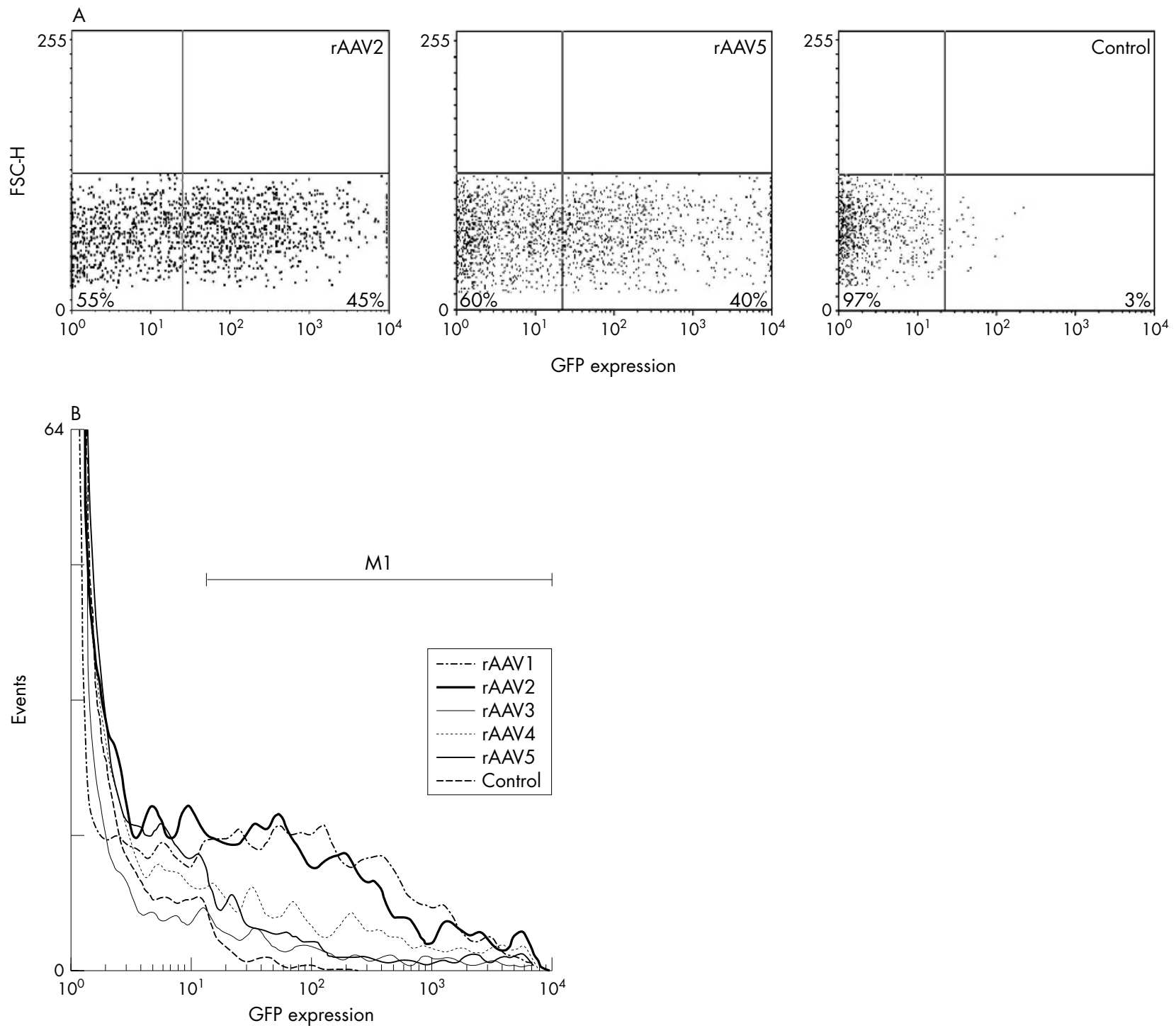

Figure 7 Flow cytometric analysis of GFP expression in rAAV transduced FLS. Human FLS were incubated with rAAV2.GFP or rAAV5.GFP at a multiplicity of infection of 100. After 72 hours, the cells were washed and analysed for GFP expression by FACS. Flu-1 plotted against FSC-H showed $45 \%$ (left panel, rAAV2) and 40\% (middle panel, rAAV5) GFP positive cells, compared with $3 \%$ in control cells (right panel), p $<0.05$ (A). Differences between rAAV2 and rAAV5 were not significantly different. In a histogram comparing GFP expression of control cells with all five rAAV serotypes, only differences between rAAV2 or rAAV5 and control or rAAV1, 3, or 4 proved significant using the Mann-Whitney $U$ test $(B)(p<0.05)$. Representative histogram of three independent experiments is shown.

titres only slightly above background (fig 5). Importantly, no cross reactivity was found for the two serotypes (data not shown).

\section{Transduction of human FLS}

Having shown that rAAV2 and rAAV5 can transduce rat synovium, we investigated the potential of both serotypes to transduce primary human FLS obtained from patients with RA. For this purpose we used rAAV vectors expressing GFP. FLS were incubated with the different rAAV serotypes and transgene expression was visualised after 72 hours by fluorescent microscopy (fig 6). Both serotypes could transduce human FLS with high efficiency, although no clear difference was seen between rAAV2 and rAAV5. To quantify the percentage of GFP expressing cells, FLS were transduced using five rAAV serotypes as described and GFP expression was evaluated by FACS analysis (fig 7). Both rAAV2 and rAAV5 resulted in significant numbers of GFP expressing cells (45\% and 40\%, respectively) compared with control (fig 7A). Compared with rAAV1, 3, and 4, rAAV2 and rAAV5 transduced significantly more FLS (fig 7B), $\mathrm{p}<0.05$.

\section{DISCUSSION}

rAAV vectors have gained much attention owing to their ability to mediate efficient transduction of both dividing and non-dividing cells and their ability to induce long term gene expression in the absence of toxicity. Over the past decade, rAAV vectors derived predominantly from serotype 2 were generated and investigated in vivo. The recent discovery of AAVs other than serotype 2 has enabled the generation of pseudotyped rAAV vectors. Until now, no studies of gene transfer to the inflamed joint have been carried out with nonserotype- 2 vectors. Therefore, we compared the transduction efficiencies of titre-matched rAAVs derived from serotypes 15, in synovial tissue of rats with AIA. The efficiency of gene expression was evaluated by enzymatic staining and by determining the amount of GC present in the joints. In this comparative study we found that direct injection of rAAV5 
into the ankle joints of rats with AIA resulted in the highest synovial transduction as demonstrated by the expression level of $\beta$-Gal, followed by a much lower expression using rAAV2. Analysis of the gDNA isolated from the joints confirmed these results.

In a second experiment we investigated the transgene expression of rAAV2 and rAAV5 at different time points. Both serotypes demonstrated marked expression over time, which was already present 1 week after injection. Of importance, $\beta$ Gal protein expression using rAAV5 was higher at all time points, confirmed by higher levels of mRNA encoding $\beta-G a l$. The fact that the gDNA profile did not parallel $\beta$-Gal expression could be explained, in part, by the relative stability of the $\beta$-Gal protein, resulting in prolonged presence of the protein. Although $\beta$-Gal is a foreign protein and possibly immunogenic, we did not observe differences in paw swelling or cellularity between rAAV injected and control animals (data not shown).

rAAV2 has previously been shown to mediate long term gene transfer in a number of tissues, including synovial tissue. ${ }^{8-10}{ }^{34-36}$ The feasibility of direct in vivo gene transfer to rat and murine arthritic joints has also been demonstrated. In most of the studies, rAAV2 genome persisted within joints for at least 100-200 days. ${ }^{81136}$ One study reported long term expression after rAAV2 gene transfer to the murine synovium for up to 7 months. ${ }^{9}$ The expression pattern of rAAV2 after intra-articular injection in mice has been variable, varying from synovial lining cells ${ }^{36}$ to chondrocytes, ${ }^{11}$ and myocytes. ${ }^{89}$ In our study, morphological analysis suggested that the cells expressing $\beta$-Gal were mainly synovial fibroblasts. Because these cells are thought to stay in the synovial tissue for long periods of time, this would allow long term transgene expression in the joint, with minimal spreading of transduced cells to peripheral tissues. In addition to the intimal lining layer, cells in the synovial sublining were transduced as well, maximising the potential of therapeutic protein production throughout the synovial tissue.

Serotype-specific affinities for cell surface attachment and internalisation receptors may, at least in part, account for the difference in the level of transgene expression between the different serotypes. Heparan sulphate proteoglycans, ${ }^{37}$ integrins, ${ }^{38}$ and fibroblast growth factor receptor $1^{39}$ are important receptors for rAAV2. Recently, N-linked sialic acid ${ }^{40}$ and platelet derived growth factor receptor ${ }^{41}$ were identified as coreceptors for AAV5, and their expression in vivo correlates well with the transduction profile of rAAV5.$^{41}$ In addition, trafficking of rAAV5 to the nucleus or its uncoating might be more efficient than for the other serotypes, explaining the higher number of GC and gene expression observed with rAAV5.

Having shown the feasibility of direct in vivo gene transfer to rat synovium, we investigated the transduction efficiency of rAAV to human FLS derived from patients with RA, which is crucial for using this vector for local human gene therapy. FLS have the highest residence in the human synovium and have a low mitotic rate. ${ }^{542}$ Therefore, FLS are likely to express transduced genes for a considerable length of time, even if the transgene is located episomally. In contrast with rAAVI, 3 , and 4, synovial fibroblasts isolated from the joints of patients with RA could be transduced with high efficiency in vitro using both rAAV2 and rAAV5. No significant differences were found between these two serotypes, suggesting that factors other than differences in affinity for cell surface receptors contribute to the different tropism seen in vivo. The transduction of human macrophages was most efficient using rAAV5, but did result in only $2 \%$ GFP positive cells (data not shown).

Some studies investigating the effect of repeated administration of $\mathrm{rAAV}$ indicate that an immune response generated after the first administration may prevent retreatment. ${ }^{43}$ We found that local rAAV2 injection in the joint clearly induces more neutralising antibodies in rat serum than rAAV5, which induced neutralising antibody levels only slightly above background. No antibodies were detected before injection of the vectors. This indicates that a marked humoral immune response is mounted against rAAV2, while the capsid of rAAV5 is less immunogenic. Importantly, no cross reactivity was seen between antibodies raised against rAAV2 and rAAV5, suggesting that re-administration could be applied using different serotypes. It should be noted that an estimated $80 \%$ of the human population carry antibodies to the capsid proteins of wild-type AAV2, and 30-70\% demonstrate the presence of neutralising anti-capsid antibodies. ${ }^{21}{ }^{44}$ In contrast, neutralising antibodies against AAV5 are rare. Moreover, endogenous sequences of AAV5 suggesting previous infection with this serotype could not be detected in a large diverse group of people. ${ }^{45}$ Together, these observations are important for the choice of an rAAV serotype vector for clinical applications, favouring the use of rAAV5.

In summary, our results show that rAAV5 is more efficient in transducing rat synovial tissue in vivo, and both rAAV2 and rAAV5 can efficiently transduce human RA synoviocytes in vitro. In addition, we showed little to no humoral immune response to rAAV5 in rat AIA. Of the five rAAV serotypes tested, rAAV5 appears to be an excellent candidate vector for local gene therapy in patients with RA, allowing long term expression of the transgene limited to the synovial compartment.

\section{ACKNOWLEDGEMENTS}

We thank Dr Marc R Kok for his contributions and critical review of the manuscript.

\section{Authors' affiliations \\ J Adriaansen, S W Tas, P L Klarenbeek, M J B M Vervoordeldonk, \\ P P Tak, Division of Clinical Immunology and Rheumatology, AMC, University of Amsterdam, Amsterdam, The Netherlands \\ A C Bakker, Amsterdam Molecular Therapeutics, Amsterdam, The Netherlands \\ F Apparailly, Unité de recherches d'immunopathologie des maladies tumorales et auto-immunes INSERM U475, Montpellier, France G S Firestein, Division of Rheumatology, Allergy, and Immunology, University of California San Diego, La Jolla, California, USA C Jorgensen, Service d'Immuno-rhumatologie, CHU Lapeyronie, Montpellier, France}

\section{REFERENCES}

1 Maini RN, Elliott M, Brennan FM, Williams RO, Feldmann M. TNF blockade in rheumatoid arthritis: implications for therapy and pathogenesis. APMIS 1997; 105:257-63.

2 Jiang $Y$, Genant HK, Watt I, Cobby M, Bresnihan B, Aitchison R, et al. A multicenter, double-blind, dose-ranging, randomized, placebo-controlled study of recombinant human interleukin-1 receptor antagonist in patients with rheumatoid arthritis: radiologic progression and correlation of Genant and Larsen scores. Arthritis Rheum 2000;43:1001-9.

3 Moreland LW, Baumgartner SW, Schiff MH, Tindall EA, Fleischmann RM, Weaver AL, et al. Treatment of rheumatoid arthritis with a recombinant human tumor necrosis factor receptor (p75)-Fc fusion protein. N Engl J Med 1997;337:141-7.

4 Elliott MJ, Maini RN, Feldmann M, Kalden JR, Antoni C, Smolen JS, et al. Randomised double-blind comparison of chimeric monoclonal antibody to tumour necrosis factor alpha (cA2) versus placebo in rheumatoid arthritis. Lancet 1994;344:1105-10.

5 Lalor PA, Mapp PI, Hall PA, Revell PA. Proliferative activity of cells in the synovium as demonstrated by a monoclonal antibody, Ki67. Rheumatol Int 1987;7:183-6.

6 Grimm D, Kay MA. From virus evolution to vector revolution: use of naturally occurring serotypes of adeno-associated virus (AAV) as novel vectors for human gene therapy. Curr Gene Ther 2003;3:281-304.

7 Snyder RO. Adeno-associated virus-mediated gene delivery. J Gene Med 1999;1:166-75.

8 Pan RY, Chen SL, Xiao X, Liu DW, Peng HJ, Tsao YP. Therapy and prevention of arthritis by recombinant adeno-associated virus vector with delivery of interleukin-1 receptor antagonist. Arthritis Rheum 2000;43:289-97. 
9 Watanabe S, Imagawa T, Boivin GP, Gao G, Wilson JM, Hirsch R. Adenoassociated virus mediates long-term gene transfer and delivery of chondroprotective IL-4 to murine synovium. Mol Ther 2000;2:147-52.

10 Zhang HG, Xie J, Yang P, Wang Y, Xu L, Liu D, et al. Adeno-associated virus production of soluble tumor necrosis factor receptor neutralizes tumor necrosis factor alpha and reduces arthritis. Hum Gene Ther 2000;11:2431-42.

11 Goater J, Muller R, Kollias G, Firestein GS, Sanz I, O'Keefe RJ, et al. Empirical advantages of adeno-associated viral vectors in vivo gene therapy for arthritis. J Rheumatol 2000;27:983-9.

12 Chan JM, Villarreal G, Jin WW, Stepan T, Burstein H, Wahl SM. Intraarticular gene transfer of TNFR:Fc suppresses experimental arthritis with reduced systemic distribution of the gene product. Mol Ther 2002;6:727-36.

13 Moss RB, Rodman D, Spencer LT, Aitken ML, Zeitlin PL, Waltz D, et al. Repeated adeno-associated virus serotype 2 aerosol-mediated cystic fibrosis transmembrane regulator gene transfer to the lungs of patients with cystic fibrosis: a multicenter, double-blind, placebo-controlled trial. Chest 2004; 125:509-21.

14 Flotte TR, Brantly ML, Spencer LT, Byrne BJ, Spencer CT, Baker DJ, et al. Phase I trial of intramuscular injection of a recombinant adeno-associated virus alpha 1-antitrypsin (rAAV2-CB-hAAT) gene vector to AAT-deficient adults. Hum Gene Ther 2004;15:93-128.

15 High KA. Clinical gene transfer studies for hemophilia B. Semin Thromb Hemost 2004;30:257-67.

16 Duan D, Sharma P, Yang J, Yue Y, Dudus L, Zhang Y, et al. Circular intermediates of recombinant adeno-associated virus have defined structural characteristics responsible for long-term episomal persistence in muscle tissue. $J$ Virol 1998;72:8568-77.

17 Hamilton H, Gomos J, Berns KI, Falck-Pedersen E. Adeno-associated virus site-specific integration and AAVS1 disruption. J Virol 2004;78:7874-82.

18 Chao H, Liu Y, Rabinowitz J, Li C, Samulski RJ, Walsh CE. Several log increase in therapeutic transgene delivery by distinct adeno-associated viral serotype vectors. Mol Ther 2000;2:619-23.

19 Grimm D, Zhou S, Nakai H, Thomas CE, Storm TA, Fuess S, et al. Preclinical in vivo evaluation of pseudotyped adeno-associated virus vectors for liver gene therapy. Blood 2003;102:2412-19.

20 Handa A, Muramatsu S, Qiu J, Mizukami H, Brown KE. Adeno-associated virus (AAV)-3-based vectors transduce haematopoietic cells not susceptible to transduction with AAV-2-based vectors. J Gen Virol 2000:81(P+ 8):2077-84.

21 Erles K, Sebokova P, Schlehofer JR. Update on the prevalence of serum antibodies (IgG and $\lg M$ ) to adeno-associated virus (AAV). J Med Virol 1999;59:406-11.

22 Peden CS, Burger C, Muzyczka N, Mandel RJ. Circulating anti-wild-type adeno-associated virus type 2 (AAV2) antibodies inhibit recombinant AAV2 (rAAV2)-mediated, but not rAAV5-mediated, gene transfer in the brain. J Virol 2004;78:6344-59.

23 Rabinowitz JE, Rolling F, Li CW, Conrath H, Xiao WD, Xiao X, et al. Cross packaging of a single adeno-associated virus (AAV) type 2 vector genome into multiple AAV serotypes enables transduction with broad specificity. J Virol 2002;76:791-801.

24 Grimm D, Kern A, Rittner K, Kleinschmidt JA. Novel tools for production and purification of recombinant adenoassociated virus vectors. Hum Gene Ther 1998;9:2745-60

25 Grimm D, Kay MA, Kleinschmidt JA. Helper virus-free, optically controllable, and two-plasmid-based production of adeno-associated virus vectors of serotypes 1 to 6. Mol Ther 2003;7:839-50.

26 Zolotukhin S, Byrne BJ, Mason E, Zolotukhin I, Potter M, Chesnut K, et al. Recombinant adeno-associated virus purification using novel methods improves infectious titer and yield. Gene Ther 1999;6:973-85.

27 Tak PP, Gerlag DM, Aupperle KR, van de Geest DA, Overbeek M, Bennett BL, et al. Inhibitor of nuclear factor kappaB kinase beta is a key regulator of synovial inflammation. Arthritis Rheum 2001;44:1897-907.
28 Nguyen KHY, Boyle DL, McCormack JE, Chada S, Jolly DJ, Firestein GS. Direct synovial gene transfer with retroviral vectors in rat adjuvant arthritis. J Rheumatol 1998;25:1118-25.

29 Kraan MC, Haringman JJ, Ahern MJ, Breedveld FC, Smith MD, Tak PP. Quantification of the cell infiltrate in synovial tissue by digital image analysis. Rheumatology (Oxford) 2000;39:43-9.

30 Kraan MC, Smith MD, Weedon H, Ahern MJ, Breedveld FC, Tak PP. Measurement of cytokine and adhesion molecule expression in synovial tissue by digital image analysis. Ann Rheum Dis 2001;60:296-8.

31 Kraan MC, Reece RJ, Smeets TJ, Veale DJ, Emery P, Tak PP. Comparison of synovial tissues from the knee joints and the small joints of rheumatoid arthritis patients: implications for pathogenesis and evaluation of treatment. Arthritis Rheum 2002;46:2034-8.

32 Smeets TJ, Kraan MC, Versendaal J, Breedveld FC, Tak PP. Analysis of serial synovial biopsies in patients with rheumatoid arthritis: description of a control group without clinical improvement after treatment with interleukin 10 or placebo. J Rheumatol 1999;26:2089-93.

33 Alvarogracia JM, Zvaifler NJ, Brown CB, Kaushansky K, Firestein GS. Cytokines in chronic inflammatory arthritis. 6. Analysis of the synovial-cells involved in granulocyte-macrophage colony-stimulating factor production and gene-expression in rheumatoid-arthritis and its regulation by IL- 1 and tumornecrosis-factor-alpha. J Immunol 1991;146:3365-71.

34 Xiao W, Berta SC, Lu MM, Moscioni AD, Tazelaar J, Wilson JM. Adenoassociated virus as a vector for liver-directed gene therapy. J Virol 1998;72:10222-6.

35 Lo WD, Qu G, Sferra TJ, Clark R, Chen R, Johnson PR. Adeno-associated virus-mediated gene transfer to the brain: duration and modulation of expression. Hum Gene Ther 1999;10:201-13.

36 Pan RY, Xiao X, Chen SL, Li J, Lin LC, Wang HJ, et al. Disease-inducible transgene expression from a recombinant adeno-associated virus vector in a rat arthritis model. J Virol 1999;73:3410-17.

37 Summerford C, Samulski RJ. Membrane-associated heparan sulfate proteoglycan is a receptor for adeno-associated virus type 2 virions. J Virol 1998; 72: 1438-45.

38 Summerford C, Samulski RJ. Viral receptors and vector purification: new approaches for generating clinical-grade reagents. Nat Med 1999;5:587-8.

39 Qing K, Mah C, Hansen J, Zhou S, Dwarki V, Srivastava A. Human fibroblast growth factor receptor 1 is a co-receptor for infection by adeno-associated virus 2. Nat Med 1999;5:71-7.

40 Kaludov N, Brown KE, Walters RW, Zabner J, Chiorini JA. Adeno-associated virus serotype 4 (AAV4) and AAV5 both require sialic acid binding for hemagglutination and efficient transduction but differ in sialic acid linkage specificity. J Virol 2001;75:6884-93.

41 Di Pasquale G, Davidson BL, Stein CS, Martins IS, Scudiero D, Monks A, et al. Identification of PDGFR as a receptor for AAV-5 transduction. Nat Med 2003;9:1306-12.

42 Coulton LA, Henderson B, Bitensky L, Chayen J. DNA synthesis in human rheumatoid and nonrheumatoid synovial lining. Ann Rheum Dis 1980;39:241-7.

43 Moskalenko M, Chen L, van Roey M, Donahue BA, Snyder RO, McArthur JG, et al. Epitope mapping of human anti-adeno-associated virus type 2 neutralizing antibodies: implications for gene therapy and virus structure. $J$ Virol 2000;74:1761-6.

44 Chirmule N, Xiao W, Truneh A, Schnell MA, Hughes JV, Zoltick P, et al. Humoral immunity to adeno-associated virus type 2 vectors following administration to murine and nonhuman primate muscle. J Virol 2000;74:2420-5

45 Gao G, Vandenberghe LH, Alvira MR, Lu Y, Calcedo R, Zhou X, et al. Clades of adeno-associated viruses are widely disseminated in human tissues. $J$ Virol 2004;78:6381-8. 